\title{
O Movimento pela Saúde dos Povos: ação global em defesa do direito universal à saúde
}

\author{
David Legge1,2, Camila Giugliani3,4, Alicia Stolkiner5, Ligia Giovanella6
}

DOI: 10.1590/0103-11042020\$100

BEM-VINDOS, BEM-VINDAS A ESTE SUPLEMENTO ESPECIAL da 'Saúde em Debate', com foco no trabalho do Movimento pela Saúde dos Povos (MSP), uma rede global de militantes da saúde e organizações ativistas que trabalham além das fronteiras para tornar realidade a visão de 1978 de 'Saúde para Todos'.

Esta edição especial é uma iniciativa do Centro Brasileiro de Estudos de Saúde (Cebes) e da Associação Latino-Americana de Medicina Social (Alames) para conclamar por uma ação global pelo direito universal à saúde.

Embora tenha havido melhorias nos indicadores agregados de saúde nas últimas décadas, as desigualdades em saúde aumentaram e cresceu o número absoluto de pessoas que vivem em ambientes inseguros e de alto risco e que não têm acesso aos cuidados de saúde necessários ${ }^{1,2}$. Ademais da ampliação das desigualdades, o fantasma da fome, deslocamentos populacionais e conflitos decorrentes do aquecimento global e da degradação ambiental alastram-se.

Em certo grau, esses riscos originam-se no peso da pegada humana nos ecossistemas globais (embora a responsabilidade por esse ônus não seja compartilhada igualmente entre populações). Não obstante, as falhas de governança que permitem essa degradação e impedem ações efetivas são econômicas e políticas. O capitalismo, como sistema econômico global, enfrenta instabilidades cada vez mais profundas. Capacidades produtivas subutilizadas contribuem para a redução do emprego (principalmente aqueles de salários decentes), do consumo e investimentos. A fuga de capital dos investimentos produtivos para a especulação avança e leva a mais bolhas, colapsos e crises. O neoliberalismo, o modo predominante de governança desde os anos 1980, está direcionado para proteger as elites globais das consequências das crises, por meio de políticas que exacerbam os desequilíbrios econômicos, conduzem à degradação ecológica e aprofundam crises.

O MSP atua em prol das condições sociais para alcançar boa saúde para todos, abordando os fatores determinantes das desigualdades e da degradação ambiental. O MSP trabalha para o acesso universal aos cuidados de saúde necessários, de maneira a também enfrentar as barreiras políticas e econômicas às reformas institucionais necessárias.

A 'teoria da mudança global' do MSP centra-se na dinâmica da mobilização social; trabalhando com comunidades que estão na linha de frente da privação e dos riscos; explorando as diferentes maneiras pelas quais a crise econômica global afeta os cuidados de saúde e as condições de vida localmente. O MSP busca a união de ativistas da saúde para além de fronteiras, limites e diferenças. Congrega ativistas que enfrentam suas distintas privações e riscos, e trabalham juntos para superar as dinâmicas e forças globais comuns a esses desafios.

Essa 'convergência' de movimentos sociais se estende para além do setor saúde. O MSP entende que questões similares estão sendo enfrentadas em muitos outros setores de ação: na agroecologia,

\footnotetext{
1 La Trobe University Melbourne, Austrália. dlegge@phmovement.org

2 People's Health Movement (PHM) Melbourne, Austrália.

3 Universidade Federal do Rio Grande do Sul (UFRGS) - Porto Alegre (RS), Brasil.

4 Movimento pela Saúde dos Povos (MSP) - Porto Alegre (RS), Brasil.

5 Universidad de Buenos Aires (UBA) - Buenos

Aires, Argentina.

6 Fundação Oswaldo Cruz (Fiocruz), Escola Nacional de Saúde Pública Sérgio Arouca (Ensp) - Rio de Janeiro (RJ), Brasil.
} 
nos sindicatos, no meio ambiente, nas questões de gênero e indígenas, na ciência e inovação. Ao mesmo tempo, movimentos sociais se organizam, atuam e se articulam em todos esses diferentes setores.

Uma grande variedade de análises e histórias do ativismo do MSP são compartilhadas nesta edição da 'Saúde em Debate'. Esses artigos ilustram as conexões entre as necessidades locais de saúde e a economia política global e as maneiras pelas quais os ativistas da saúde estão enfrentando as necessidades locais de forma a contribuir para a construção de um movimento global.

Baum, Sanders e Narayan descrevem e analisam as origens do MSP e suas formas de atuação e discutem questões estratégicas que o Movimento enfrenta na conjuntura atual. Uma delas, é a aproximação e real participação dos movimentos sociais nos processos decisórios no âmbito da governança global em saúde, foco de um dos principais projetos do MSP em nível global, o Observatório da Organização Mundial da Saúde (WHO Watch). Rocha, Martins e Farias analisam esse tema a partir de suas experiências de participação como watchers em artigo que discute as possibilidades de influência da sociedade civil nos processos decisórios da governança global na Organização Mundial da Saúde (OMS). O WHO Watch é uma iniciativa do MSP que se propõe a estimular a democratização dos processos decisórios da OMS. A atuação do MSP na formação de ativistas por meio da Universidade Internacional para a Saúde dos Povos é relatada por Zuniga que sintetiza a história de um projeto singular de formação em El Salvador que reuniu ativistas da saúde da sociedade civil e profissionais do Ministério da Saúde para compartilhar perspectivas sobre o desenvolvimento do sistema de saúde e ações sobre a determinação social da saúde. Outro projeto fundamental do MSP, o relatório Global Health Watch, cuja última edição foi lançada em 2018, é apresentado na resenha deste número por Falcão et al.

A concepção do Buen Vivir, uma das bases fundantes do MSP na América Latina é discutida por Bobatto, Segovia e Rosas como caminho alternativo ao modelo de desenvolvimento hegemônico atual. O Buen Vivir é entendido como projeto político de vida; um processo de bem-estar coletivo que potencializa a vida em harmonia e equilíbrio com a mãe natureza e o cosmos.

Raghunandan e Jayaprakash examinam a atuação do Movimento de Ciência do Povo (People's Science Movement, agora parte do MSP Índia) na resposta à tragédia de Bhopal. Destacam o papel de Amit Sengupta nesse processo, líder do MSP, que faleceu tragicamente em dezembro de 2018. A Índia, as Filipinas e a Europa são o pano de fundo para a discussão trazida por Nandi e Vračar sobre o impacto das reformas neoliberais no campo da saúde, que enfraqueceram os sistemas públicos de saúde dos países, levando à comercialização dos cuidados de saúde. Arteaga-Cruz et al. trazem mais histórias de luta no ensaio que parte da pergunta 'Financiar sistemas nacionais de saúde com ganhos vindos da indústria extrativista é compatível com a visão de direito à saúde'? Os autores destacam a necessidade de fortalecer o vínculo entre as lutas pelo direito à saúde e a resistência contra o extrativismo.

De São Luís no Brasil, Torres et al., por meio de entrevista com a irmã Anne Wihbey, pioneira do MSP no Brasil, trazem uma história que resume a interação entre o local e o global na reprodução das necessidades de saúde e conta como um grupo de ativistas que trabalhou para atender às necessidades locais em consonância com processos mais gerais. Nos tempos atuais, no Rio de Janeiro, temos a experiência do Movimento Nenhum Serviço de Saúde a Menos, um exemplo de resistência contra a precarização dos serviços públicos de saúde, relatada por Saffer et al.

$\mathrm{O}$ artigo de Giugliani et al., de Porto Alegre, apresenta resultados de um projeto de pesquisa-ação que começou explorando se (e por que) as instituições de controle social no Sistema Único de Saúde (SUS) brasileiro estavam enfraquecidas e finalizou com um projeto de revitalização do espaço verde em uma escola estadual, em uma experiência singular de participação social.

Urrego-Rodriguez revisa as lutas dos povos indígenas na Colômbia pela concretização do direito 
à saúde. As lutas do povo colombiano pelo direito à saúde são também foco do artigo de Torres-Tovar et al., fruto de um projeto investigativo vinculado ao MSP. Ainda no contexto de uma pesquisa-ação, o coletivo italiano Grup-pa (Bodini et al.) propõe uma interessante e relevante discussão sobre a saúde como algo comum, aberto à participação de todos e todas, construída a partir de práticas coletivas e solidárias, vinculando a concepção de determinação social da saúde com o conhecimento e as práticas compartilhadas nas commons e ressaltando o seu potencial transformador.

De volta para a Índia, tendo como base a história trágica da morte de 150 crianças por síndrome de encefalite aguda no estado de Bihar, Venkatachalam et al. argumentam sobre a importância da análise interseccional de determinantes no entendimento das iniquidades, compreendendo que os fatores produtores dessas mortes são múltiplos e entrecruzados.

Entre as organizações ativistas e redes filiadas ao MSP, o suplemento destaca a atuação do Cebes e da Alames. A atuação do Cebes um dos principais protagonistas do movimento da reforma sanitária brasileira, que culminou na criação de um sistema público universal de saúde no Brasil, o SUS, é relatada por Costa et al. As alianças estratégicas e convergências entre o MSP e a Alames são analisadas por Stolkiner et al.

Por fim, convidamos todos os leitores e leitoras deste número especial a conhecer e difundir a Declaração da IV Assembleia Mundial pela Saúde dos Povos, que reafirma que a luta pela saúde é a luta por um mundo mais equitativo, justo e solidário. Um chamado para a ação.

Os legados de dois dos maiores líderes do MSP, Amit Sengupta e David Sanders, que nos deixaram recentemente, são inspiração e compromisso para perseguir a 'Saúde para Todos'. Os emocionantes depoimentos de vários ativistas do MSP não deixam dúvidas quanto aos ensinamentos e ações transformadoras desses dois gigantes.

Boa leitura!

\section{Colaboradores}

Legge D (0000-0002-4552-1470)*, Giugliani C (0000-0002-2652-5214)*, Stolkiner A (0000-00019372-7556)* e Giovanella L (0000-0002-6522-545X)* contribuíram igualmente na elaboração do manuscrito.

\section{Referências}

1. World Health Organization;World Bank. Tracking Universal Health Coverage 2017 Global Monitoring Report [internet]. Geneva:WHO; Washington: The World Bank. 2017. [acesso em 2020 jan 16]. Disponível em: https://apps.who.int/iris/bitstream/handle/10665/259817/9789241513555-eng. pdf? sequence $=1 \#$ page $=11$.
2. Organization for Economic Co-operation and Development. Health for Everyone?:Social Inequalities in Health and Health Systems [internet]. OECD Health Policy Studies. Paris: OECD Publishing, Paris; 2019. [acesso em 2020 jan 16]. Disponível em: https://www.oecd.org/publications/health-for-everyone-3c8385do-en.htm.
${ }^{*}$ Orcid (Open Researcher and Contributor ID). 